\title{
Environmental sensibility
}

\author{
Arnold BERLEANT \\ Long Island University (USA)
}

\begin{abstract}
Aesthetics is fundamentally a theory of sensible experience. Its scope has expanded greatly from centering on the arts and scenic nature to the full range of appreciative experience. Expanding the range of aesthetics raises challenging questions about the experience of appreciation. Traditional accounts are inadequate to identify and illuminate the perceptual experiences that these new applications evoke. Considering the range of environmental and everyday occasions aesthetically changes aesthetics into a descriptive and not necessarily celebratory study of sensible experience, for it must now accommodate a complete range of negative as well as positive values. This paper develops an analysis of the multiple dimensions of environmental sensibility.
\end{abstract}

Keywords: aesthetic theory, aesthetic engagement, appreciation, environment, perceptual experience, sensibility

\section{Introduction}

It is common to think of aesthetics as a theory that accounts for the beauty or the pleasing quality of things. This is not far from the mark. When philosophers speak of aesthetics as a scholarly discipline, they usually associate it with the philosophy of art and the special value that the arts and nature possess. Over the past several decades, however, the arts and aesthetic practices have continued the direction of the past century in expanding their domain still more rapidly. The application of aesthetic values to environment is one instance of this expansion, and environmental aesthetics has emerged as an important part of the enlarged scope of aesthetics. The scope of environment itself has grown to include not only the scenic landscape but the urban landscape and the industrial landscape, including their negative aspects. More recently, aesthetics has been applied to still other domains of experience, such as the aesthetics of everyday life, the aesthetics of food, the aesthetics of community, political aesthetics, and still others. Moreover, the growing awareness of other cultures and their traditions of aesthetic satisfaction have forced our thinking to expand into still other dimensions.

Expanding the range of aesthetics raises challenging questions about the experience of appreciation. Traditional accounts of aesthetic appreciation are inadequate to identify and illuminate the perceptual pleasures that these new applications evoke. But not only does an enlarged range of aesthetic appreciation recognize beauties beyond the arts. It also must account for the range of aesthetic perception into the oneiric, the bizarre, the terrible, and the banal, while the social and political significance of aesthetic values has led to the recognition of a wide range of such values, not all of them positive. (Berleant, 2010)

These challenges to aesthetic understanding have made the task both more important and more obstinate. For our concerns now include not only art and the beauty of nature but the full range of normative experience, and this has given aesthetics increased significance and has produced greater confusion. What do these domains of experience have in common? Is there something that all these modes of experience share in considering them aesthetic? This is the challenging question for aesthetics in our time.

P1・ Opening | Ouverture -53 
The key to understanding the aesthetic lies, I believe, in the etymology of that word. The term "aesthetics" is a transliteration of the Greek "aisthēsis," which means perception by the senses. Natural beauty and the arts have long been the focus of aesthetics, but in recent decades not only has the appreciation of nature received renewed attention; nature has been enlarged to signify environment understood more broadly to include the city and the built landscape in general. What is more, aestheticians have extended their scope to embrace the world of everyday experience. In these domains, the disinterested contemplation endorsed traditional aesthetics is inappropriate and different ways of explaining aesthetic pleasure have emerged. ${ }^{1}$ These developments in art and aesthetic appreciation have strained the theoretical unity of traditional aesthetics, which cannot easily accommodate these changes. Thus, with over a century of innovation in the arts and the vast enlargement and complexity of appreciative experience, the customary rubrics of explanation have become increasingly inadequate and even irrelevant.

\section{From objects to experience}

From the hindsight of the present, the succession of disruptive movements that occupied the world of art from the late nineteenth century to the present day can be regarded as a rejection of the convention in thinking of art as an object, a distinctive object. The gradual and increasing emancipation from close representation led, in modern painting, to ways of giving pictorial form to the perception of light, of movement, of mass, and of form, transforming them from abstractions into perceptual experience. In the visual arts, impressionism, cubism, futurism, and dada began a direction that transformed the art object into an occasion for perceptual, sensible engagement.

This changes aesthetics into a descriptive and not necessarily celebratory study of perceptual experience, for it must now accommodate a complete range of negative as well as positive values. Nor is aesthetic theory confined to the fine arts and nature only: an aesthetic dimension pervades the human world. What emerges is the understanding that aesthetic appreciation is not an object-centered response that requires a psychological remove and a disinterested attitude. Rather, it is a complex multi-sensory perceptual engagement by means of a cultivated sensibility.

This broad vision of sensible experience must be expanded still further. It must be seen as a field experience. ${ }^{2}$ Sensible experience is part of an existential context that includes the geological strata that underlie all activity, the modifications of the earth's surface and the structures that result from human activities in fashioning the immediate conditions of living, the behaviors that promote sustenance and wellbeing, and the social relations and patterns that constitute the cultural activities of human living under the particular conditions of time and place. Living, then, is a perceptually selective, discriminating process in which everyone receives and contributes. It is a condition of continuities within which we make distinctions, separations, and divisions based on need, customary practices, and tradition. The perceptual factors of this field reflect the full range of sensation and sensible awareness as they are filtered and discriminated in participatory activities. We inhabit, then, a field of sensate activity that rests on sensation but as sensible perception infused by and related to all the

1. This has been a principal preoccupation of my own work in which I have proposed the unity of perceiver and object in an aesthetic field, and developed aesthetic engagement as characterizing appreciative experience. The present essay carries this effort still further by developing aesthetic sensibility as the central factor in appreciation.

2. The concept of an aesthetic field describes the complex context of which appreciative experience is a part. See my book, The Aesthetic Field: A Phenomenology of Aesthetic Experience (Springfield, III: C. C. Thomas, 1970), second edition with a new Preface (Cybereditions: 2001).

http://cybereditions.com/spis/runisa/dII?SV:cyTheBooksTmp

54 - 2nd International Congress on Ambiances, Montreal 2012 
conditions that affect and qualify human experience. My purpose here is to identify and begin to explore aesthetic sensibility in the context of environment.

\section{Sensibility}

The historical and theoretical development I have outlined culminates in the insight that aesthetics is, at its base, a theory of sensibility. Such a generalized aesthetic illuminates the arts of the past as well as of our time. It enables us to recognize the presence of a pervasive aesthetic aspect in every experience, including environmental, whether such experience is uplifting or demeaning, exalting or brutal. ${ }^{3}$ It makes the constant expansion of the range of art and of aesthetic experience both plausible and comprehensible. How, then, can we understand sensibility?

By sensibility I mean perceptual awareness that is developed, focused, and informed. It is more than simple sensation, more than sense perception. Perhaps one can consider it educated sensation. It requires the perceptual knowledge and skills that we are continually enhancing in and through our encounters and activities. Aesthetic sensibility develops and uses this capacity at the deliberate center of conscious experience. In Western cultures, the arts have been the primary medium for promoting such awareness, and we can consider changes in artistic style, the emergence of new movements, and even entire historical periods in the arts as fundamentally changes in sensibility. Looking at culture change more broadly, we can regard fashion, etiquette, and behavior patterns in general as expressions of the prevailing sensibility of a place and time. So while sensibility is not a term common in the literature of aesthetics, what it denotes is not new or unfamiliar. Human activities seem always to have exhibited qualitative interests in fashioning craft objects as well as decorative and ornamental ones, together with those we now call artistic. All of these display an attention and delight in features and qualities we now call aesthetic.

The multiple facets of life experience become strata that the fine arts often draw on and extend. Ordinary sense experience is rarely isolated or channeled, and appropriations of sensation as "subjective," mechanical, or purely physiological are simplistic and presumptive rather than purifications. Sensibility, informed by sensory experience, is therefore not purely "subjective," mental, or exclusively private but a character of awareness by living humans in a context that is seamlessly natural, social, structural, and cultural.

\section{Environmental sensibility}

Using sensibility as a key to aesthetic apprehension can illuminate our understanding of the appreciative experience of the arts. But aesthetic sensibility has particularly rich possibilities for identifying and enhancing the aesthetic experience of environment. Perception of the built environment is through multi-sensory bodily engagement. Such aesthetic engagement transforms our environmental perception of space, mass, density, force, and directionality when apprehended not as abstractions but as direct experiences in the acute sensory experience of everyday life. Indeed, it is in relation to environment that aesthetic sensibility may have its most extended development, for environment is the broadest, most perceptually inclusive human context. The sensibility involved in most of the arts, while expansive, tends to center around one or more of the basic senses, although the senses are never discrete but collaborate in all aesthetic experience. Environment, however, involves a whole body experience. Even more than the arts, environment articulates the holistic, contextual character of experience, and focused attention is a precondition of aesthetic sensibility. Let me offer some examples that may suggest other, similar ones.

3. I have developed the idea of the normative range of aesthetic value in Sensibility and Sense: The Aesthetic Transformation of the Human World.

P1 - Opening | Ouverture -55 
One environmental occasion potentially rich with significance is the liminal experience of passing through a doorway or under an arch. This may become a mobile body process of transmigration. The height and shape of the doorway or arch are obviously significant, ranging from the lattice arch in a rose garden to the monumental stone Arc de Triomphe at the end of Champs-Élysées. A circular doorway in a Chinese garden provides a different body experience from a post and lintel one. Including the space beyond the doorway carries the example further and can have a powerful effect. Important, also, about these examples is that they are whole body experiences involving active participation. Moreover, they do not center around a particular sensory modality like sight but engage a wide spectrum of sense receptors. In these respects they are strong models of environmental sensibility.

Understanding environment as a perceptual process is transformative. Environment is no longer an object, it is not surroundings, nor is it separate and apart from the human participant. Rather we recognize that the human is an integral constituent of environment, acting and re-acting as part of its constant flux. Environmental sensibility is an enhanced sensory awareness of what we may call the "life field." It engages all the senses not as discrete avenues of perception but synaesthetically, with multiply fused sensory awareness. Particularly active are the general body senses: haptic sensory awareness, kinesthetic consciousness, the somatic apprehension of space, mass, and movement, and directionality as these are grasped physically as well as visually.

The search for the satisfaction of sensible experience comes from a thirst for positive perceptual value and can be fulfilled in the perceptual satisfactions of the rich forms and details of the world of human life. This returns the meaning of aesthetics to its origins and reaffirms the critical place of sensation and sense perception within the aura of environmental sensibility. At the same time, environmental sensibility shows that sense perception is never simple sensation or pure perception but a complex, multi-faceted field experience. When such experience is predominately environmental, it takes on an aesthetic character in which sensory awareness is focused and cultivated. This is what is meant by sensibility, and it leads to recognizing the importance of the aesthetic character of all environmental experience.

\section{References}

Berleant A. (2010), Sensibility and Sense: The Aesthetic Transformation of the Human World, Exeter, Imprint Academic

Sartwell C. (2010), Political Aesthetics, Ithaca, Cornell University Press

Panagia D.(2006), The Poetics of Political Thinking, Durham, NC, Duke UP

Panagia D. (2009), The Political Life of Sensation, Durham, NC, Duke UP

\section{Author}

Arnold Berleant is Professor of Philosophy (Emeritus) at Long Island University (USA). His interests range over aesthetics, the arts, ethics, and social philosophy, and he has lectured and written widely in these areas, both nationally and internationally. Berleant is the author of numerous articles as well as eight books on aesthetics, the arts, and especially the aesthetics of environment. He is also the founding editor of the on-line journal, Contemporary Aesthetics. 